\title{
Methylmalonic acidemia without homocystinuria
}

INSERM

\section{Source}

INSERM. (1999). Orphanet: an online rare disease and orphan drug data base.

Methylmalonic acidemia without homocystinuria. ORPHA:293355

Methylmalonic acidemia is an inborn error of vitamin B12 metabolism characterized by gastrointestinal and neurometabolic manifestations resulting from decreased function of the mitochondrial enzyme methylmalonyl-CoA mutase. 